\title{
Effects of solute permeability on permeation and solute rejection in membrane filtration
}

\begin{tabular}{|r|l|}
\hline Journal: & Chemical Engineering \& Technology \\
\hline Manuscript ID & ceat.201700203.R1 \\
\hline Wiley - Manuscript type: & Research Article \\
\hline Date Submitted by the Author: & n/a \\
\hline Complete List of Authors: & $\begin{array}{l}\text { Lopes, Gustavo H.; Aix Marseille Univ, CNRS, Centrale Marseille, M2P2 } \\
\text { Ibaseta, Nelson; Aix Marseille Univ, CNRS, Centrale Marseille, M2P2 } \\
\text { Guichardon, Pierrette; Aix Marseille Univ, CNRS, Centrale Marseille, M2P2 } \\
\text { Haldenwang, Pierre; Aix Marseille Univ, CNRS, Centrale Marseille, M2P2 }\end{array}$ \\
\hline Keywords: & $\begin{array}{l}\text { permeate flux, concentration polarization, solute permeability, Reverse } \\
\text { Osmosis, solute rejection }\end{array}$ \\
\hline
\end{tabular}

SCHOLARONE ${ }^{\text {m }}$

Manuscripts 


\title{
Effects of solute permeability on permeation and solute rejection in membrane filtration
}

Gustavo H. Lopes, Nelson Ibaseta, Pierrette Guichardon" ${ }^{*}$ Pierre Haldenwang

Aix Marseille Univ, CNRS, Centrale Marseille, M2P2, Marseille, France

* corresponding author:

Centrale Marseille

38, rue Frédéric Joliot Curie

13451 Marseille Cedex 20, France

pierrette.guichardon@centrale-marseille.fr, +33(0)491054360

\begin{abstract}
$\underline{\text { Abstract }}$
Membrane solute permeability plays a role in the buildup of concentration polarization in pressure-driven crossflow filtration processes, and thus in the determination of the permeate flux, solute rejection, retentate flux and concentration. We numerically examine reverseosmosis desalination with membranes of fixed solvent permeability, but of variable selectivity with respect to the solute. The study highlights an intricate coupling between retentate and filtrate properties. In particular, it reveals that, for given values of solute permeability and feed concentration, there is a maximum operating pressure that optimizes solute rejection regardless of the feed salinity. The conditions leading to this and to other peculiar behaviors for permeation fluxes and concentrations are identified.
\end{abstract}

\section{$\underline{\text { Keywords }}$}

Permeate flux, solute rejection, concentration polarization, solute permeability, reverse osmosis

\section{Introduction}

Reverse osmosis (RO) and nanofiltration (NF) are mainly applied for seawater desalination, wastewater treatment and water reclamation, for ultrapure water production and in process industry niches $[1,2]$. These processes use membrane separation to achieve high purification and relatively high solvent permeation rates [1]. The development and optimization of these separation techniques typically rely on abundant, laborious, often costly pilot experiments while the prediction of their performances remains underexplored. In this context, the use of predictive models and the application of the subsequent fundamental knowledge would be valuable.

The performance of pressure-driven membrane filtration processes is determined by an intimate interaction between the transport properties of the membranes and the hydrodynamics and mass transfer taking place inside a membrane-bound channel. It is well known that this interaction gives rise to a reversible accumulation of solute in a mass

$$
\text { Wiley-VCH }
$$


boundary layer on the filtrating surface of the membrane, the so-called concentration polarization layer [3-6]. Combined with osmosis, concentration polarization hinders solvent permeation and increases solute passage into the filtrate (permeate) in addition to playing a part in scaling and fouling [3, 4].

New membranes are under development with the aim of maximizing the permeation rate by enhancing the membrane permeability to the solvent while ensuring highest selectivity, so as to keep the solute concentration in the permeate as low as possible. Unfortunately, the effort is partly wasted, as increased permeation inherently causes enhanced concentration polarization. Reducing this concentration polarization can nonetheless be achieved by disturbing the concentration layers with eddy-promoting spacers put into the flow channel [7]. Notwithstanding, the question may be raised as to whether tailoring the selectivity of the membrane can induce intensified permeation, irrespective of the polarization conditions. The role played by the membrane solute permeability here has not been discussed enough. This is the point we herein investigate.

This work follows the publication by Lopes et al. [8], which demonstrated the adequacy of the numerical model developed by the authors for predicting permeate fluxes and solute rejection obtained experimentally in RO and tight NF in flat and spiral-wound geometries. The current article begins with a summary of the model and a description of the simulations. It then presents the results, discussions and conclusions about the impact of solute permeability at different operating conditions upon the fundamental behavior of an ideal separation process, as well as on its two main outputs: permeate flux and solute rejection. The study considers numerous orders of magnitude of solute permeability from $0 \mathrm{~m} \mathrm{~s}^{-1}$ to $10^{-6} \mathrm{~m} \mathrm{~s}^{-1}$ and a solvent permeability in the range of $\mathrm{RO}\left(10^{-12} \mathrm{~m} \mathrm{~Pa}^{-1} \mathrm{~s}^{-1}\right)$.

\section{Model description}

As the model we used is described extensively in $[6,8,9]$, only its main elements will be given here. The model considers a liquid solution of one solvent and one solute in laminar, steady, incompressible crossflow filtration (tangential filtration) along a two-dimensional planar symmetric channel of axial and transverse coordinates $Z$ and $X$, respectively, the channel walls being permeable to both solvent and solute. Axial velocity $(W)$, transverse velocity $(U)$, permeate flux $\left(U_{\mathrm{w}}\right)$, solute concentration (or concentration polarization) $(C)$, gauge pressure $(P)$ and permeate concentration $\left(C_{\mathrm{p}}\right)$ are considered as functions of $Z$ and $X$. The input parameters are all easily accessible experimentally: two properties of the membrane (permeability to the solvent, $I^{-1}$, and permeability to the solute, $B$ ), two properties of the membrane filtration module (channel length, $L$, and channel half-height, $d$ ), two operating conditions (feed pressure, $P_{\text {in }}$, and axial feed velocity, $W_{\text {in }}$ ) and four properties of the solution (solute feed concentration, $C_{\mathrm{in}}$, solution mass density, $\rho$, solution viscosity, $\mu$, and solute diffusivity in the solvent, $D$ ). A schematic is sketched in Fig. 1. Note that subscripts "w", "p" and "in" refer to the membrane surface on the retentate side (wall), the membrane surface on the permeate side, and the inlet (or feed) conditions, respectively.

$$
\text { Wiley-VCH }
$$




\section{(Fig. 1)}

Fouling is not considered while osmotic counter-effects are taken into account. $\rho, \mu$ and $D$ are equal to their values in the feed. The solution-diffusion model $[1,10]$ describes locally the transmembrane solvent and solute fluxes, as in Eq. (1) and Eq. (2), respectively:

$U_{\mathrm{w}}(Z)=I^{-1}[P(Z)-\Delta \Pi(Z)]$

$C_{\mathrm{p}}(Z) U_{\mathrm{w}}(Z)=B\left[C_{\mathrm{w}}(Z)-C_{\mathrm{p}}(Z)\right]$

where

$U_{w}(Z)=U(d, Z)$

$C_{w}(Z)=C(d, Z)$

and $\Delta \Pi$ is the osmotic pressure difference between the retentate and permeate sides of the membrane,

$\Delta \Pi(Z)=\Pi\left[C_{\mathrm{w}}(Z)\right]-\Pi\left[C_{\mathrm{p}}(Z)\right]$

calculated based on the van't Hoff's osmotic pressure law,

$\Pi=i R T C$

where $i$ is the van't Hoff's factor, $R$ is the ideal gas constant and $T$ is the solution temperature.

The numerical solutions are calculated at each grid point in half of the channel via a secondorder finite difference scheme which solves the continuity equation, the two-dimensional Navier-Stokes equations and the solute conservation equation simultaneously [6]. The system is handled in dimensionless form under Prandtl's hypotheses $[6,8,9]$ whereby diffusion of momentum and mass in the longitudinal (axial) flow direction is negligible compared with that in the transverse direction. These equations are solved in the filtration channel only (flow domain), whereas membrane transport takes the form of boundary conditions (Eqs. (1) and (2)). As will be seen, the flow in the whole domain will depend on the membrane transport properties.

The simulations consider the desalination of aqueous sodium chloride solutions at $25^{\circ} \mathrm{C}$ by membranes of solvent permeability $I^{-1}=5 \times 10^{-12} \mathrm{~m} \mathrm{~Pa}^{-1} \mathrm{~s}^{-1}$ (typical for RO) and solute permeability, $B$, tuned from $0 \mathrm{~m} \mathrm{~s}^{-1}$ (membrane impermeable to the solute, i.e., perfectly permselective) through $10^{-8} \mathrm{~m} \mathrm{~s}^{-1}$ and $10^{-7} \mathrm{~m} \mathrm{~s}^{-1}$ (typical for RO) up to $10^{-6} \mathrm{~m} \mathrm{~s}^{-1}$. The flow channel reproduces the length of an industrial membrane module with six identical membranes arranged in series, thus $L=6 \mathrm{~m}$ and $d=5 \times 10^{-4} \mathrm{~m}$. As presented in Tab. 1 , feed 
concentrations ranging from that of low-concentration brackish water up to that of seawater are simulated. $P_{\text {in }}$ varies from $1.5 \times 10^{5} \mathrm{~Pa}$ to $60 \times 10^{5} \mathrm{~Pa}$. $W_{\text {in }}$ is $0.1 \mathrm{~m} \mathrm{~s}^{-1}$. Empirical laws are used to estimate $\rho, \mu$ and $D$ [11]. The computational domain is discretized into 1000 transverse and 8000 axial grid points.

(Tab. 1)

\section{Results}

\subsection{Permeate fluxes}

Let us first consider the behavior of the averaged permeate flux measured by experimentalists, $U_{\text {av }}$, equivalent to the local permeate flux averaged along the membrane length [8]. The classic influence of the inlet pressure on it is depicted in Fig. 2 for three feed concentrations using the nondimensional "three-Péclet-numbers" representation introduced by Haldenwang et al. [12].

(Fig. 2)

Accordingly, $P e_{\mathrm{av}}$ is the averaged (subscript av) permeation Péclet number (dimensionless permeate flux), $P e_{\text {in }}$ is the inlet pure-solvent Péclet number (nondimensional inlet pressure), and $P e_{\mathrm{in}}^{\text {osm }}$ is the inlet osmotic (superscript osm) Péclet number (dimensionless inlet solute concentration):

$$
\begin{aligned}
& P e_{\mathrm{av}}=U_{\mathrm{av}} \frac{d}{D} \\
& P e_{\mathrm{in}}=P_{\mathrm{in}} I^{-1} \frac{d}{D} \\
& P e_{\mathrm{in}}^{\mathrm{osm}}=\Pi_{\mathrm{in}} I^{-1} \frac{d}{D}
\end{aligned}
$$

This representation is convenient because the three Péclet numbers are of the same order of magnitude. Hence, for low solute concentrations, i.e., low values of $P e_{\mathrm{in}}^{\mathrm{osm}}, P e_{\mathrm{av}}$ is close to but always lower than $P e_{\text {in }}$. As concentration polarization increases, so does the gap between $P e_{\mathrm{av}}$ and $P e_{\mathrm{in}}$. Finally, if the membrane is fully impermeable to the solute, $P e_{\mathrm{av}}$ will be positive only if $P e_{\text {in }}$ is higher than $P e_{\text {in }}^{\text {osm }}$.

Tab. 2 exemplifies the values of $P_{\text {in }}$ and $P e_{\text {in }}$. As expected, Fig. 2 shows that the averaged permeate flux increases with the inlet (or applied) pressure. For the lowest solute concentration $\left(P e_{\mathrm{in}}^{\mathrm{osm}}=0.13\right)$, concentration polarization remains weak as long as the inlet pressure is low; for $P e_{\mathrm{in}} \leq 1$ in particular, $P e_{\mathrm{av}} \approx P e_{\mathrm{in}}$. However, as $P e_{\mathrm{in}}$ rises, concentration polarization becomes significant; the increase in effective operating pressure tends to vanish (term in brackets in Eq. (1)) and so does the permeation. Two observations can be made regarding higher feed concentrations. First, whenever the membrane is fully selective, and for

$$
\text { Wiley-VCH }
$$


the solvent to pass into the permeate, the value of the abscissa-intercept increases with $P e_{\text {in }}^{\text {osm }}$ because $P e_{\text {in }}$ must exceed $P e_{\text {in }}^{\text {osm }}$, as concluded from Eq. (1). Second, it is reasonable to expect $P e_{\mathrm{av}}$ to grow linearly with $P e_{\mathrm{in}}-P e_{\mathrm{in}}^{\mathrm{osm}}$ provided that concentration polarization is negligible, and to infer that the coupling of polarization and osmotic pressure is significant whenever the growth of $P e_{\mathrm{av}}$ with $P e_{\mathrm{in}}-P e_{\mathrm{in}}^{\mathrm{osm}}$ tends to deviates from linearity even for low pressures. However, the slopes of the linear segments are very different depending on $P e_{\mathrm{in}}^{\text {osm }}$ : higher feed concentrations intensify polarization and osmosis, ergo reducing permeation.

(Tab. 2)

It is also noteworthy to analyze the dependence of the permeate flux on the solute permeability value. The units of $B$ allow us to envisage it as the diffusion velocity of the solute across the membrane and thus to express the permeability values in nondimensional form by dividing them by the solute diffusion velocity in the feed channel, $D / d$. This gives rise to the dimensionless membrane solute permeability, $\delta$, whose correspondence with the values of $B$ in this study is presented in Tab. 3:

$\delta=B \frac{d}{D}$

(Tab. 3)

Fig. 2 evaluates three orders of magnitude of $\delta$ and reveals that the more solute-permeable (or the less permselective) the membrane, the higher the permeate fluxes for a given solvent permeability. This tendency is even greater when the inlet concentration rises and at lower feed pressures. In the cases where this tendency is clearest, $P e_{\mathrm{av}}$ for a membrane of $\delta \sim 10^{-1}$ is almost 4 times higher than for a membrane of $\delta \sim 0$ when $P e_{\mathrm{in}}^{\text {osm }}$ is 1.46 and $P e_{\text {in }}$ is 1.7. Also, $P e_{\mathrm{av}}$ for $\delta \sim 10^{-1}$ is more than 3 times higher than for $\delta \sim 0$ when $P e_{\mathrm{in}}^{\mathrm{osm}}$ is 5.12 and $P e_{\text {in }}$ is 6 . In fact, as will be demonstrated in the following subsection, an intricate mechanism accounts for the reduction of the osmotic pressure difference between both sides of the membrane. This happens when the membrane becomes more permeable to the solute, leading to higher permeation rates. Under our simulation conditions, the effects of the solute permeability upon this mechanism with respect to $P e_{\mathrm{av}}$ cannot be neglected unless the order of magnitude of $\delta$ is below the threshold of $10^{-2}$ (in which case there is overlap with $\delta=0$ [6]). In accordance with this rationale, it is worth noticing that the results simulated here for mild polarization conditions (low $P e_{\text {in }}$ ) for the two membranes of lowest solute permeability are comparable to those calculated with equation numbered (41) in Haldenwang et al [12].

\subsection{Axial and transverse profiles}

Dimensionless concentrations, fluid velocities, fluxes and transverse coordinate are henceforth represented by the same symbols as their homonyms but in the small letter version. Fig. 3 and Fig. 4 represent the nondimensional axial profiles of the concentration on the membrane 
surface, $c_{\mathrm{w}}$, permeate concentration, $c_{\mathrm{p}}$, osmotic pressure difference, $O s\left(c_{\mathrm{w}}-c_{\mathrm{p}}\right)$, and local permeate flux, $u_{\mathrm{w}}$ :

$$
\begin{aligned}
& c_{\mathrm{w}}=\frac{C_{\mathrm{w}}}{C_{\mathrm{in}}} \\
& c_{\mathrm{p}}=\frac{C_{\mathrm{p}}}{C_{\mathrm{in}}} \\
& O s=\frac{\Pi_{\mathrm{in}}}{P_{\mathrm{in}}} \\
& u_{\mathrm{w}}=\frac{U_{\mathrm{w}}}{P_{\mathrm{in}} I^{-1}}
\end{aligned}
$$

(Fig. 3a, Fig. 3b, Fig. 3c)

(Fig. 4a, Fig. 4b)

In Eq. (13), Os is the osmotic number [8]. Profiles in Fig. 3 and 4 are represented as functions of the dimensionless axial coordinate, $\zeta$ :

$\zeta=\frac{Z}{L}$

We first focus on the case of membranes totally impermeable to the solute $(\delta=0): c_{\mathrm{p}}$ is null and therefore an osmotic pressure develops only in the retentate. As a consequence of the solvent passage into the permeate, the concentration of the retentate grows as it flows forward in the membrane channel, and so does the membrane surface concentration $\left(c_{\mathrm{w}}\right)$. Figs. 3a-3c show the increase in $c_{\mathrm{w}}$ along $\zeta$ and Figs. $4 \mathrm{a}-4 \mathrm{~b}$ the consequent increase in osmotic pressure difference and the reduction in permeate flux. The magnitude of these effects is however dependent on the feed concentration. In fact, depending on the conditions, $c_{\mathrm{w}}$ may become from a little more than 1 up to 9 times higher than the feed concentration along the flow channel. Figs. 3a-3c and Figs. 4a-4b reveal that the dimensionless permeate flux becomes weaker at higher $P e_{\mathrm{in}}^{\mathrm{osm}}$, just as the nondimensional magnitude of concentration polarization. As a result, the rise in osmotic pressure and the consequent reduction in permeate flux are attenuated. Note that, in nondimensional form (as in Fig. $3 \mathrm{~b}$ and according to Eq. 11), concentration polarization (and thus the value of $c_{\mathrm{w}}$ ) can be proportionally lower for higher feed concentrations than for lower feed concentrations because of a lower nondimensional permeation rate at higher polarization.

The rationale changes considerably if the membrane is permeable to the solute: the transmembrane solute flux has to be taken into account in the calculations. The solute concentration in the permeate is no longer zero. An osmotic pressure develops in the permeate, and not only in the retentate. This alone would tend to increase the permeation rate. Somewhat surprisingly however, Figs. 3a-3c reveal that $c_{\mathrm{w}}$ is higher for a membrane of high solute permeability $\left(\delta \sim 10^{-1}\right)$ than when $\delta=0$. This itself would cause $u_{\mathrm{w}}$ to decrease. The final result of these opposing tendencies upon $u_{\mathrm{w}}$ is observed in Figs. $4 \mathrm{a}-4 \mathrm{~b}$. The rise in $c_{\mathrm{p}}$

$$
\text { Wiley-VCH }
$$


counterbalances that in $c_{\mathrm{w}}$, i.e., $c_{\mathrm{w}}-c_{\mathrm{p}}$ diminishes and so does the local osmotic pressure difference, resulting in higher permeate fluxes. This contributes, in turn, to the rise in $c_{\mathrm{w}}$, as previously observed.

A crossflow is not one-dimensional by definition. While the previous paragraphs insisted on the role of $U$ on the establishment of the polarization layer by advection of solute onto the membrane surface, the influence of the axial shearing generated upon this layer by $W$ should not be neglected $[6,8]$. Consider:

$c=\frac{C}{C_{\mathrm{in}}}$

$w=\frac{W}{W_{\text {in }}}$

$x=\frac{X}{d}$

Fig. 5a reveals that, for higher $\delta$, the axial velocity, $w$, is lower at all transverse positions $(x)$ as a consequence of the strong increase in solvent permeation seen in Fig. $5 b$ as an increased transverse velocity, $u$ (crossflow velocity, whose maximum value is $u_{\mathrm{w}}$, as illustrated in Fig. 1). Hence, for higher $\delta$, less solute is swept downstream by the flow, intensifying the concentration polarization layer, as shown in Fig. 5c. It is interesting to note that there is a certain compensation between $w$ and $u$, which is reflected by the inverted positions that straight and dashed lines have in Fig. 5a and Fig. $5 b$.

(Fig. 5a, Fig. 5b, Fig. 5c)

Fig. 5a also allows us to conclude that the retentate flow is increasingly decelerated along the membrane channel. The comparison of Fig. 5b and Fig. 5c furthermore shows that the increase in polarization in the axial direction is accompanied by a sharp reduction in the transverse velocity as the fluid flows along the filtration channel. Moreover, for the same reasons as in Fig. 2, the local values of the crossflow velocity are somewhat larger for higher $\delta$. More details on the transverse profiles of the crossflow velocity are presented in [6].

The model is also capable of calculating the magnitude of concentration polarization at different cross-sections of the flow domain. Fig. 5c depicts the axial evolution of the transverse concentration gradient along the membrane filtration channel. It is evident from Fig. $5 \mathrm{c}$ that actually not only $c_{\mathrm{w}}$ but also the whole bulk solution becomes more concentrated along the flow channel. This corroborates the usual experimental finding according to which the retentate stream is more concentrated than the feed solution. In other words, the transverse concentration profiles hypothesized by the film model, according to which the concentration boundary layer is found on the membrane surface only, $[1,4,6]$ are only found at the beginning of the flow channel. This remark underlines the limitations of the one-dimensional film model for describing a crossflow in long filtration channels [6, 9]. 
For a membrane of given solute permeability $(\delta)$, the difference between the nondimensional values of $c$ at positions $x=0$ (center of the filtration channel) and $x=1$ (membrane surface) in Fig. $5 \mathrm{c}$ is the extent of concentration polarization at each cross-section $(\zeta)$. According to Eq. 6, this value also represents the local enhancement of osmotic pressure on the retentate side caused by the buildup of the polarization layer. This enhancement is strongly related to the reduction in solvent permeation and the increase in the solute passage into the permeate, as indicated by Eq. 1 and Eq. 2, respectively. From Fig. 5c, an enhancement of approximately 2 to 3 times occurs depending on the membrane properties and the axial coordinate. The figure also confirms that the osmotic pressure on the retentate side increases with $\zeta$ (this can also be concluded from Fig. 4).

The axial pressure profiles had been analyzed beforehand according to Eq. (1) since the permeate velocity, $u_{\mathrm{w}}$, is proportional to $p(\zeta)-O s\left[c_{\mathrm{w}}(\zeta)-c_{\mathrm{p}}(\zeta)\right]$ where $p(\zeta)=P(Z) / P_{\text {in }}$ is the local pressure. These profiles are presented in reference [6]. The pressure drop was low in all cases: less than $5 \%$ at lowest feed pressure and negligible otherwise. It is interesting to realize how the influence of membrane selectivity upon the hydrodynamics of the problem extends to the pressure values. Indeed, enhanced permeation at higher values of $B$ is accompanied by a deceleration of the axial flow and so by a lower pressure drop (or increased filtration pressure). This has a retroactive effect on the solvent permeation, intensifying it [6, $13,14]$. However, the effect was minor under our simulation conditions.

\subsection{Solute rejection}

Together with the averaged permeate flux, the averaged solute rejection [8], $T R_{\mathrm{av}}$, is of prime importance for experimentalists:

$T R_{\mathrm{av}}=1-c_{\mathrm{p}_{\mathrm{av}}}$

where $c_{\mathrm{p}_{\mathrm{av}}}$ is the mean bulk concentration of the permeate solution reduced by $C_{\mathrm{in}}$ [7].

Fig. 6a represents $T R_{\mathrm{av}}$ as a function of $P e_{\text {in }}$ for several values of $\delta$ and $P e_{\mathrm{in}}^{\text {osm }}$. The solute rejection obviously diminishes when the solute permeability increases. Total rejection can only be admitted for $\delta<10^{-3}$ (or $B<10^{-8} \mathrm{~m} \mathrm{~s}^{-1}$ ). This can be more clearly distinguished in Fig. $6 \mathrm{~b}$ where all curves correspond to orders of magnitude of $c_{\mathrm{p}_{\mathrm{av}}}$ above $10^{-2}$. The remarkable finding in Fig. 6 is that the solute rejection exhibits a non-monotonical dependence on the applied pressure. On the one hand, for low pressures leading to relatively low permeate fluxes, any pressure rise will result in a higher permeate flux, which dilutes the solute in the permeate and results in a higher solute rejection. By contrast, for high pressures causing high permeate fluxes, the higher the pressure, the more severe the concentration polarization, which increases the solute transfer across the membrane and reduces the solute rejection. In other words, there is a maximum value for the operating pressure which will lead to a maximum solute rejection (possibly regarded as optimal).

(Fig. 6a, Fig. 6b)

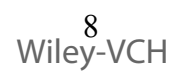


The example in Fig. 7 helps clarify the effect of $\delta$ seen in Fig. 6. From Fig. 7, the increase in $u_{\mathrm{w}}$ (due to higher solute permeability) is not sufficient for the soaring transmembrane solute flux (due to higher concentration polarization at higher $u_{\mathrm{w}}$ ), $c_{\mathrm{p}} \times u_{\mathrm{w}}$, to be diluted. Indeed, as opposed to $c_{\mathrm{p}} \times u_{\mathrm{w}}, u_{\mathrm{w}}$ depends indirectly on $\delta[6,8]$ and its sensitivity is not too high.

\title{
(Fig. 7)
}

Fig. 6 also demonstrates that the maximum value of the solute rejection that can be attained is practically independent of the inlet concentration. It however shows that the corresponding pressure increases with $P e_{\text {in }}^{\text {osm }}$.

Concentration polarization affects simultaneously, in opposite directions and to different extents, the driving forces for both solvent and solute transmembrane transport. It modifies their magnitudes and determines their axial evolutions. As such, it influences the whole process behavior and outputs. At the same time, these driving forces are also functions of the membrane transport properties (among which the solute permeability), the operating conditions and the characteristics of the filtration module. That is to say, concentration polarization is "cause and effect" of deeply convoluted aspects. Unless simulations or experiments are carried out for each set of input conditions, it is not possible to quantify concentration polarization and its effects upon solute rejection. The only statements that can be made in advance are the behaviors highlighted in the previous paragraphs leading to the non-asymptotic dependence of the solute rejection on the applied pressure.

\section{$\underline{\text { 4. Conclusions }}$}

This study has pointed out the effects of membrane selectivity on the overall hydrodynamics and bulk mass transfer in the flow channel. The membrane transport properties regarding the solute may modify concentration polarization to such significant extent as to define not only the values of solute rejection but also those of permeate flux. The reason behind this modification is an intertwined coupling between membrane transport properties, hydrodynamics, concentration polarization, osmotic pressures on the feed and permeate sides of the membrane, and pressure drop. As long as the membrane solute permeability is high, the consideration of the transmembrane solute flux, and thus of an integrated treatment coupling permeate flux and permeate concentration, should not be circumvented. This calls for an accurate estimation of the membrane transport parameters [15].

One main finding of this study is the increase in permeate flux with increasing solute permeability. This owes to the coupling between the osmotic pressures on the two sides of the membrane and the concentration polarization. This effect is significant for relatively high values of membrane solute permeability not necessarily in the range of reverse-osmosis membrane permeability values. It is useful to understand that a less selective membrane of

\author{
Wiley- $\stackrel{9}{\mathrm{CCH}}$
}


higher solute permeability might be a good choice whenever the target of the separation process is to concentrate the retentate instead of obtaining a high-purity permeate.

The second main finding is the existence of an optimal applied pressure leading to maximum solute rejection (or lowest permeate concentration) for a given feed concentration. This is the result of the combination of two regimes: the dilutive regime, where rising pressures will increase the permeate flux and result in higher solute rejection, and the concentrative regime, where even higher pressures will result in lower and even negative solute rejections. The maximum solute rejection depends on the solute permeability but is rather independent of the inlet concentration.

Some considerations apply. The effect of higher solute permeability upon the permeate flux would be lessened in modules where concentration polarization is weakened, as for example in spiral-wound modules with feed spacers. Conversely, if the osmotic pressure happens to be higher than that predicted by Eq. (6), the effect would be intensified; this is the case for some solutes whose osmotic pressure obeys a polynomial law or power law with exponents higher than one. Finally, higher solute permeability leads to higher concentrations on the membrane surface. This could be a problem in systems prone to fouling, but could be interesting for specific applications.

\section{$\underline{\text { Acknowledgement }}$}

Gustavo H. Lopes thanks the Conseil Régional de Provence-Alpes-Côte d'Azur and the École Centrale de Marseille for financing this work.

\section{Symbols used}

$\begin{array}{lll}B & {\left[\mathrm{~m} \mathrm{~s}^{-1}\right]} & \text { membrane solute permeability } \\ C & {\left[\mathrm{~mol} \mathrm{~m}^{-3}\right]} & \text { solute concentration } \\ C & {[-]} & \text { dimensionless solute concentration } \\ D & {\left[\mathrm{~m}^{2} \mathrm{~s}^{-1}\right]} & \text { solute diffusion coefficient in the feed solution } \\ d & {[\mathrm{~m}]} & \text { flow channel half-height } \\ I & {\left[\mathrm{~m}^{-1} \mathrm{~Pa} \mathrm{~s}^{-1}\right.} & \text { membrane resistance to transmembrane solvent flow } \\ I^{-1} & {\left[\mathrm{~m} \mathrm{~Pa}^{-1} \mathrm{~s}^{-1}\right]} & \text { membrane solvent permeability } \\ i & {[-]} & \text { van't Hoff's factor } \\ L & {[\mathrm{~m}]} & \text { flow channel length } \\ M & {[\%]} & \text { solute mass percentage } \\ O s & {[-]} & \text { osmotic number } \\ P & {[\mathrm{~Pa}]} & \text { hydrodynamic pressure } \\ P e & {[-]} & \text { Péclet number } \\ R & {\left[\mathrm{~J} \mathrm{~K}{ }^{-1} \mathrm{~mol}^{-1}\right]} & \text { ideal gas constant } \\ T & {[\mathrm{~K}]} & \text { solution temperature } \\ T R & {[-]} & \text { solute rejection }\end{array}$




$\begin{array}{lll}U & {\left[\mathrm{~m} \mathrm{~s}^{-1}\right]} & \text { transverse velocity } \\ u & {[-]} & \text { dimensionless transverse velocity } \\ W & {\left[\mathrm{~m} \mathrm{~s}^{-1}\right]} & \text { axial velocity } \\ w & {[-]} & \text { dimensionless axial velocity } \\ X & {[\mathrm{~m}]} & \text { transverse coordinate } \\ x & {[-]} & \text { reduced transverse coordinate } \\ Z & {[\mathrm{~m}]} & \text { axial coordinate }\end{array}$

\section{$\underline{\text { Greek symbols }}$}
$\Delta \quad[-] \quad$ difference between the feed and permeate membrane sides, respectively
$\delta \quad[-] \quad$ dimensionless membrane solute permeability
$\zeta \quad[-] \quad$ dimensionless axial coordinate
$\mu \quad[\mathrm{Pa} \mathrm{s}] \quad$ feed solution viscosity
$\Pi \quad[\mathrm{Pa}] \quad$ osmotic pressure
$\rho \quad\left[\mathrm{kg} \mathrm{m}^{-3}\right] \quad$ feed solution density

$\underline{\text { Sub-/superscripts }}$

$\begin{array}{ll}\text { av } & \text { averaged } \\ \text { in } & \text { inlet (feed, applied) conditions } \\ \text { osm } & \text { osmotic } \\ \text { p } & \text { permeate } \\ \text { w } & \text { wall (membrane surface) }\end{array}$

$\underline{\text { Abbreviations }}$

$\mathrm{NF} \quad$ nanofiltration

RO reverse osmosis

\section{$\underline{\text { References }}$}

[1] A. G. Fane, C. Y. Tang, R. Wang, in Treatise on Water Science, $1^{\text {st }}$ ed. (Ed: P. Wilderer), Elsevier Science, 2011, Ch. 4.11. DOI: 10.1016/B978-0-444-53199-5.00091-9

[2] A. Schaefer. A. Fane, T. Waite, Nanofiltration Principles and Applications, $1^{\text {st }}$ ed., Elsevier Science, 2004.

[3] H. Strathmann, in Ullmann's Encyclopedia of Industrial Chemistry, (Ed: B. Elvers), Wiley-VCH, Weinheim 2012, 514-525. DOI: 10.1002/14356007.o16_o05

[4] S. S. Sablani, M. F. A. Goosen, R. Al-Belushi, M. Wilf, Desalination 2001, 141, 269-289. DOI: 10.1016/S0011-9164(01)85005-0 
[5] R. Salcedo-Díaz, P. García-Algado, M. García-Rodríguez, J. Fernández-Sempere, F. RuizBeviá, J. Membr. Sci. 2014, 456, 21-30. DOI: 10.1016/j.memsci.2014.01.019

[6] G. H. Lopes, Ph.D. Thesis, École Centrale de Marseille 2014.

[7] A. J. Karabelas, M. Kostoglou, C. P. Koutsou, Desalination 2015, 356, 165-186. DOI: 10.1016/j.desal.2014.10.002

[8] G. H. Lopes, N. Ibaseta, P. Guichardon, P. Haldenwang, Chem. Eng. Technol. 2015, 38 (4), 585-594. DOI: 10.1002/ceat.201400654

[9] B. Bernales, P. Haldenwang, P. Guichardon, N. Ibaseta, Desalination 2017, 404, 341-359. DOI: 10.1016/j.desal.2016.09.026

[10] J. G. Wijmans, R. W. Baker, J. Membr. Sci. 1995, 107 (1-2), 1-21. DOI: 10.1016/03767388(95)00102-I

[11] V. Geraldes, V. Semião, M. N. de Pinho, J. Membr. Sci. 2001, 191, 109-128. DOI: $10.1016 / \mathrm{S} 0376-7388(01) 00458-6$

[12] P. Haldenwang, P. Guichardon, N. Ibaseta, G. Chiavassa, Int. J. Heat Mass Transfer 2010, 53 (19-20), 3898-3904. DOI: 10.1016/j.ijheatmasstransfer.2010.05.008

[13] P. Haldenwang, J. Fluid Mech 2007, 593, 463-473. DOI: 10.1017/S0022112007008622

[14] P. Haldenwang, P. Guichardon, Eur. J. Mech. B. Fluids 2011, 30 (2), 177-183. DOI: 10.1016/j.euromechflu.2010.09.007

[15] G. H. Lopes, N. Ibaseta, P. Guichardon, Desalination 2016, 387, 61-74. DOI: 10.1016/j.desal.2016.03.006

\section{$\underline{\text { Tables with headings }}$}

Tab. 1: Mass percentages $\left(M_{\mathrm{in}}\right)$ and molar concentration $\left(C_{\mathrm{in}}\right)$ of sodium chloride and their respective inlet osmotic Péclet numbers $\left(P e_{\mathrm{in}}^{\text {osm }}\right)$.

\begin{tabular}{|c|c|c|}
\hline$M_{\text {in }}(\%)$ & $C_{\text {in }}\left(\mathrm{mol} \mathrm{m}^{-3}\right)$ & $P e_{\text {in }}^{\text {osm }}$ \\
\hline 0.1 & 17.1 & 0.13 \\
\hline 1.0 & 171.1 & 1.46 \\
\hline 3.5 & 598.9 & 5.12 \\
\hline
\end{tabular}


Tab. 2: Dimensional feed pressure values $\left(P_{\text {in }}\right)$ and their nondimensional counterparts $\left(P e_{\text {in }}\right)$. The variation with $P e_{\mathrm{in}}^{\text {osm }}$ is due to the concentration-dependence of the salt diffusivity [11] in the feed solution.

\begin{tabular}{|c|c|c|}
\hline \multirow{2}{*}{$P_{\text {in }}\left(10^{5} \mathrm{~Pa}\right)$} & $P e_{\text {in }}^{\text {osm }}$ & $P e_{\text {in }}$ \\
\hline \multirow{3}{*}{0} & 0.13 & 0 \\
\cline { 2 - 3 } & 1.46 & 0 \\
\cline { 2 - 3 } & 5.12 & 0 \\
\hline \multirow{3}{*}{35} & 0.13 & 2.36 \\
\cline { 2 - 3 } & 1.46 & 2.59 \\
\cline { 2 - 3 } & 5.12 & 2.59 \\
\hline \multirow{3}{*}{45} & 0.13 & 4.72 \\
\cline { 2 - 3 } & 1.46 & 5.17 \\
\hline \multirow{3}{*}{60} & 5.12 & 5.17 \\
\cline { 2 - 3 } & 0.13 & 7.09 \\
\cline { 2 - 3 } & 1.46 & 7.76 \\
\cline { 2 - 3 } & 5.12 & 7.76 \\
\hline & 0.13 & 9.45 \\
\hline
\end{tabular}

Tab. 3: Dimensional solute permeability values $(B)$ studied in the current work and their nondimensional counterparts $(\delta)$. The variation with $P e_{\mathrm{in}}^{\text {osm }}$ is due to the concentrationdependence of the salt diffusivity [11] in the feed solution.

\begin{tabular}{|c|c|c|}
\hline$B\left(\mathrm{~m} \mathrm{~s}^{-1}\right)$ & $P e_{\mathrm{in}}^{\text {osm }}$ & $\delta$ \\
\hline \multirow{3}{*}{0} & 0.13 & 0 \\
\cline { 2 - 3 } & 1.46 & 0 \\
\cline { 2 - 3 } & 5.12 & 0 \\
\hline \multirow{3}{*}{$10^{-8}$} & 0.13 & $3.15 \times 10^{-3}$ \\
\cline { 2 - 3 } & 1.46 & $3.45 \times 10^{-3}$ \\
\cline { 2 - 3 } $10^{-7}$ & 5.12 & $3.45 \times 10^{-3}$ \\
\hline \multirow{3}{*}{$10^{-6}$} & 0.13 & $3.15 \times 10^{-2}$ \\
\cline { 2 - 3 } & 1.46 & $3.45 \times 10^{-2}$ \\
\cline { 2 - 3 } & 5.12 & $3.45 \times 10^{-2}$ \\
\cline { 2 - 3 } & 0.13 & $3.15 \times 10^{-1}$ \\
\hline & 1.46 & $3.45 \times 10^{-1}$ \\
\hline
\end{tabular}

\section{$\underline{\text { Figure legends }}$}

Fig. 1: Two-dimensional flow channel bound symmetrically by two equally permeable membranes. A crossflow occurs in the channel whereby the feed solution splits into the retentate stream and the solute-containing permeate. Process variables are described locally and vary axially and/or transversally. Sketch out of scale $(L \gg d)$. 
Fig. 2: Three-Péclet-number diagram representing the dimensionless averaged permeate flux $\left(P e_{\mathrm{av}}\right)$ as a function of the nondimensional applied pressure $\left(P e_{\mathrm{in}}\right)$ for three values of dimensionless solute concentration $\left(P e_{\mathrm{in}}^{\mathrm{osm}}\right)$. Results are represented for three values of dimensionless solute permeability $(\delta)$.

Fig. 3: Axial profiles of the nondimensional membrane and permeate concentrations, $c_{\mathrm{w}}$ and $c_{\mathrm{p}}$, respectively, for two values of nondimensional solute permeability $(\delta)$. a) $M_{\text {in }}=3.5 \%$; $P_{\text {in }}$ $=60 \times 10^{5} \mathrm{~Pa}$. b) $M_{\text {in }}=1.0 \%$; $P_{\text {in }}=60 \times 10^{5} \mathrm{~Pa}$. c) $M_{\text {in }}=0.1 \% ; P_{\text {in }}=1.5 \times 10^{5} \mathrm{~Pa}$.

Fig. 4: Axial profiles of the dimensionless osmotic pressure difference and nondimensional local permeate flux, $O s\left(c_{\mathrm{w}}-c_{\mathrm{p}}\right)$ and $u_{\mathrm{w}}$, respectively, for two values of nondimensional solute permeability $(\delta)$. a) Solutions of $M_{\text {in }}=1.0 \%$ and $M_{\text {in }}=3.5 \%$ at $P_{\text {in }}=60 \times 10^{5} \mathrm{~Pa}$. b) Solution of $M_{\text {in }}=0.1 \%$ at $P_{\text {in }}=1.5 \times 10^{5} \mathrm{~Pa}$.

Fig. 5: Transverse profiles in the channel half-height at different axial positions along the flow channel during the desalination of a solution of $M_{\text {in }}=1.0 \%$ at $P_{\text {in }}=30 \times 10^{5} \mathrm{~Pa}$ for two values of solute permeability $(\delta)$. a) Axial velocity, w. b) Transverse velocity, $u$. c) Solute concentration, $c$.

Fig. 6: Influence of the dimensionless applied pressure $\left(P e_{\text {in }}\right)$ on the overall purification for three feed concentrations $\left(P e_{\mathrm{in}}^{\mathrm{osm}}\right)$ and using membranes of different solute permeabilities $(\delta)$. a) Averaged rejection, $T R_{\mathrm{av}}$. b) Logarithm of $c_{\mathrm{p}_{\mathrm{av}}}$, the averaged solute concentration.

Fig. 7: Axial evolution of the local solute and solvent fluxes, $u_{\mathrm{w}} c_{\mathrm{p}}$ and $u_{w}$, respectively, in the case of a solution of $M_{\text {in }}=1.0 \%$ desalinated at $P_{\text {in }}=60 \times 10^{5} \mathrm{~Pa}$ for four values of dimensionless solute permeability $(\delta)$. 


\section{Short text for the table of contents section}

The coupling of concentration polarization, transmembrane solute and solvent fluxes and osmotic pressures was studied by solving the continuity, Navier-Stokes and solute transfer equations. Solvent permeation was found to rise with the value of membrane solute permeability. Moreover, there is an optimal value of inlet pressure which leads to maximum solute rejection at a given feed concentration.

\section{Graphical abstract}

(submitted online) 
Fig. 1

$297 \times 209 \mathrm{~mm}(300 \times 300$ DPI $)$ 


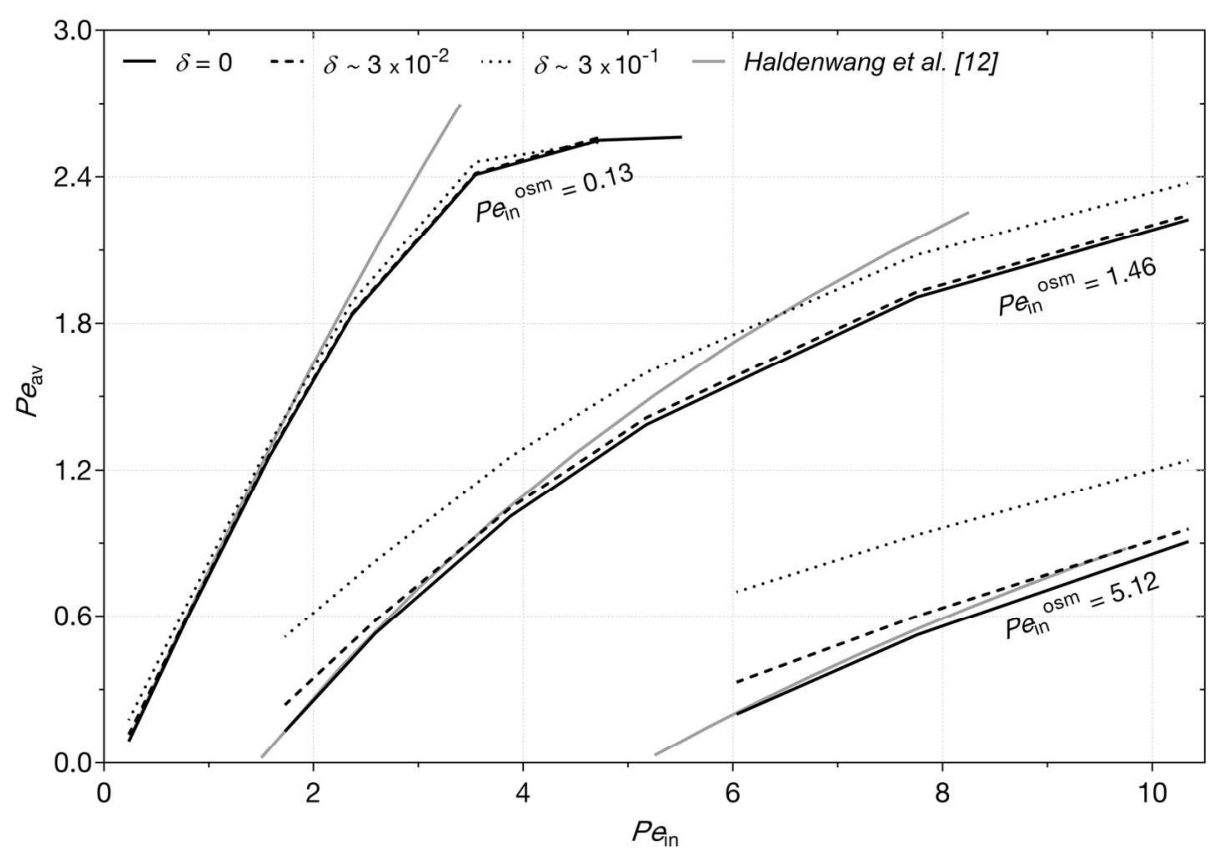

Fig. 2

$147 \times 101 \mathrm{~mm}(300 \times 300 \mathrm{DPI})$ 


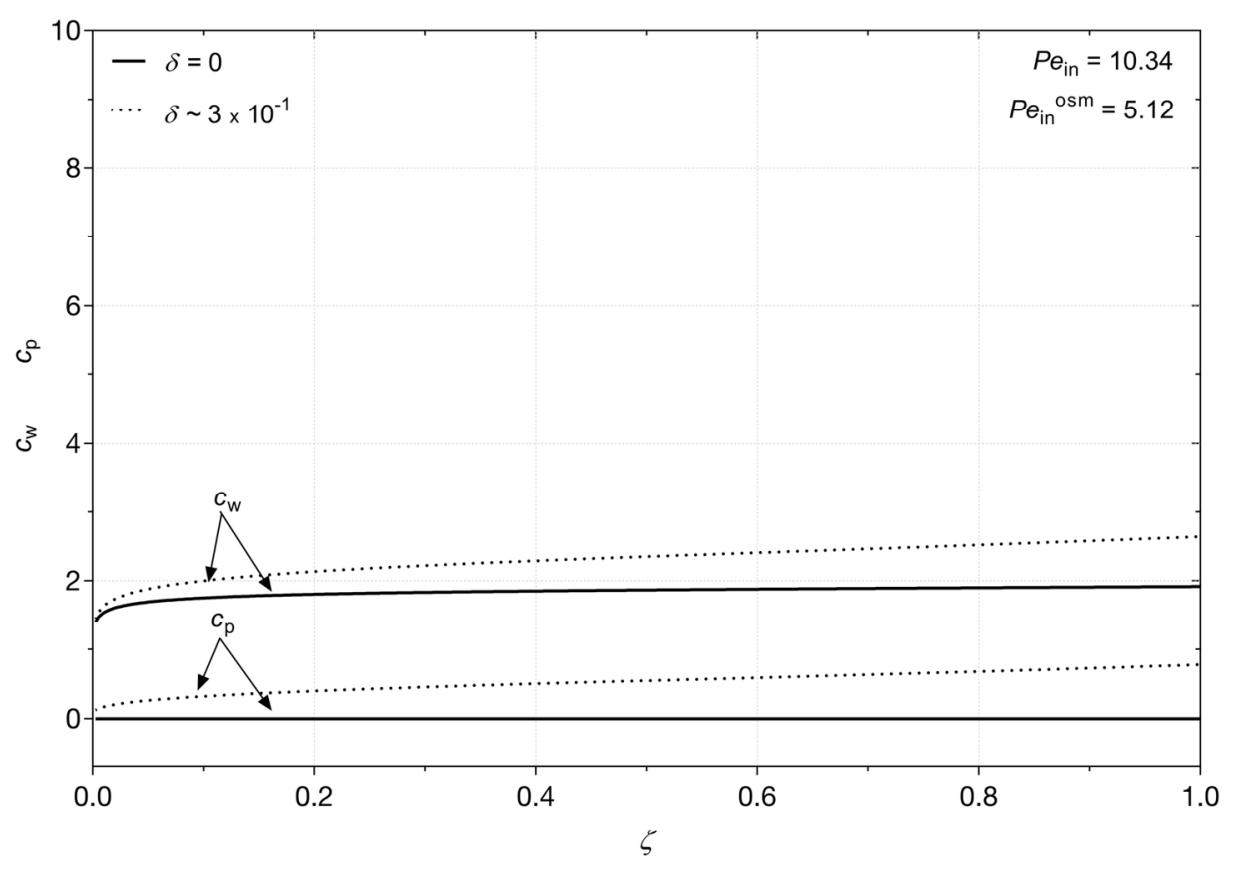

Fig. 3a

$147 \times 101 \mathrm{~mm}(300 \times 300$ DPI)

Wiley-VCH 


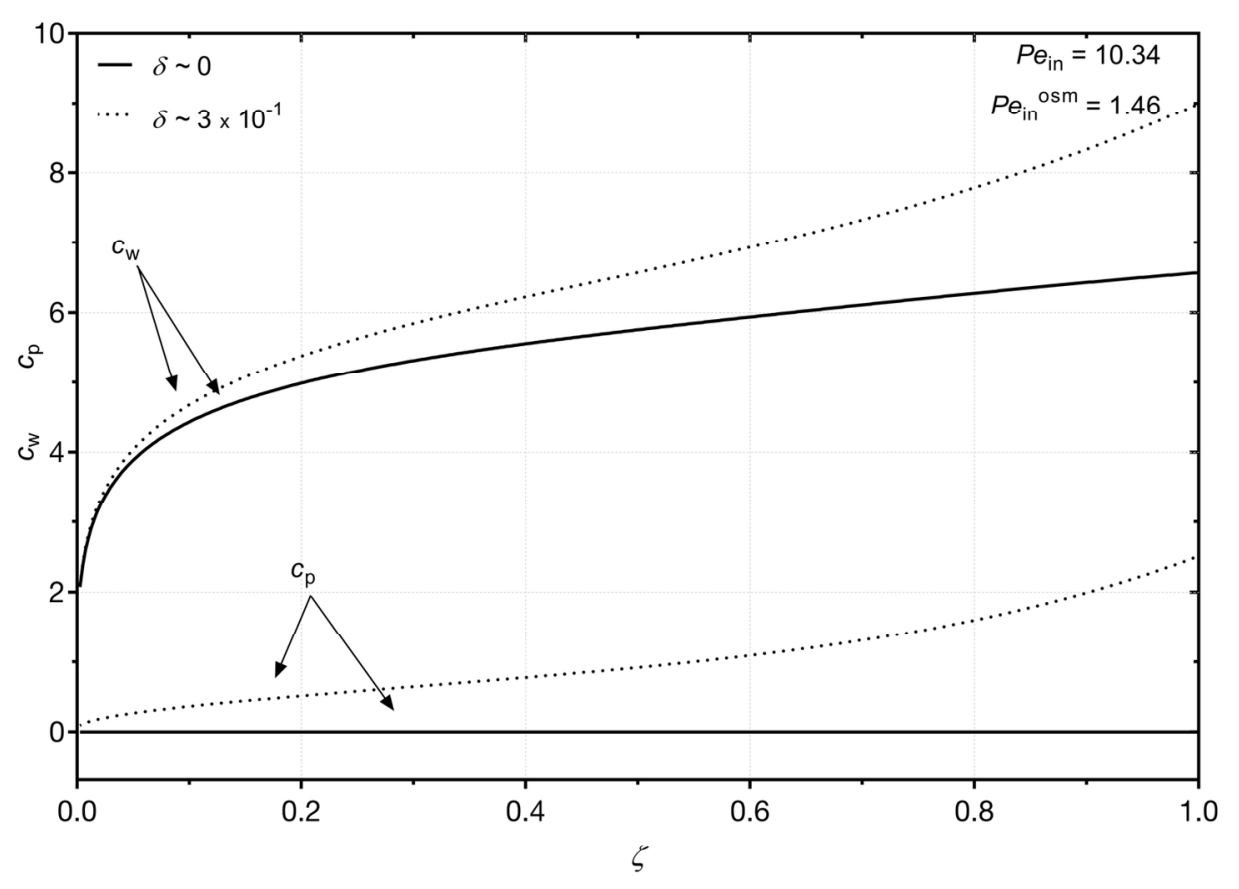

Fig. 3b

$145 \times 101 \mathrm{~mm}(300 \times 300 \mathrm{DPI})$ 


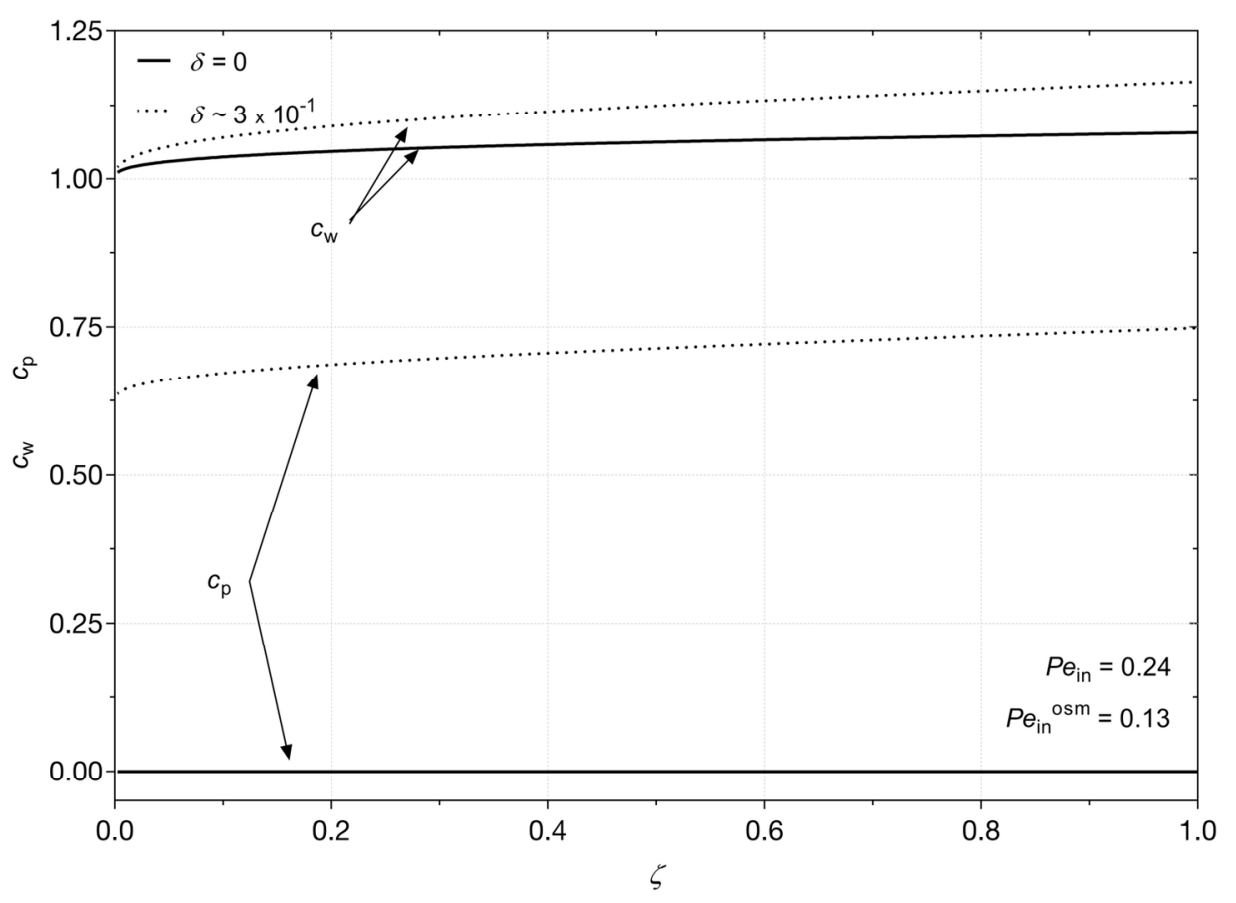

Fig. 3c

$153 \times 109 \mathrm{~mm}(300 \times 300$ DPI $)$

Wiley-VCH 


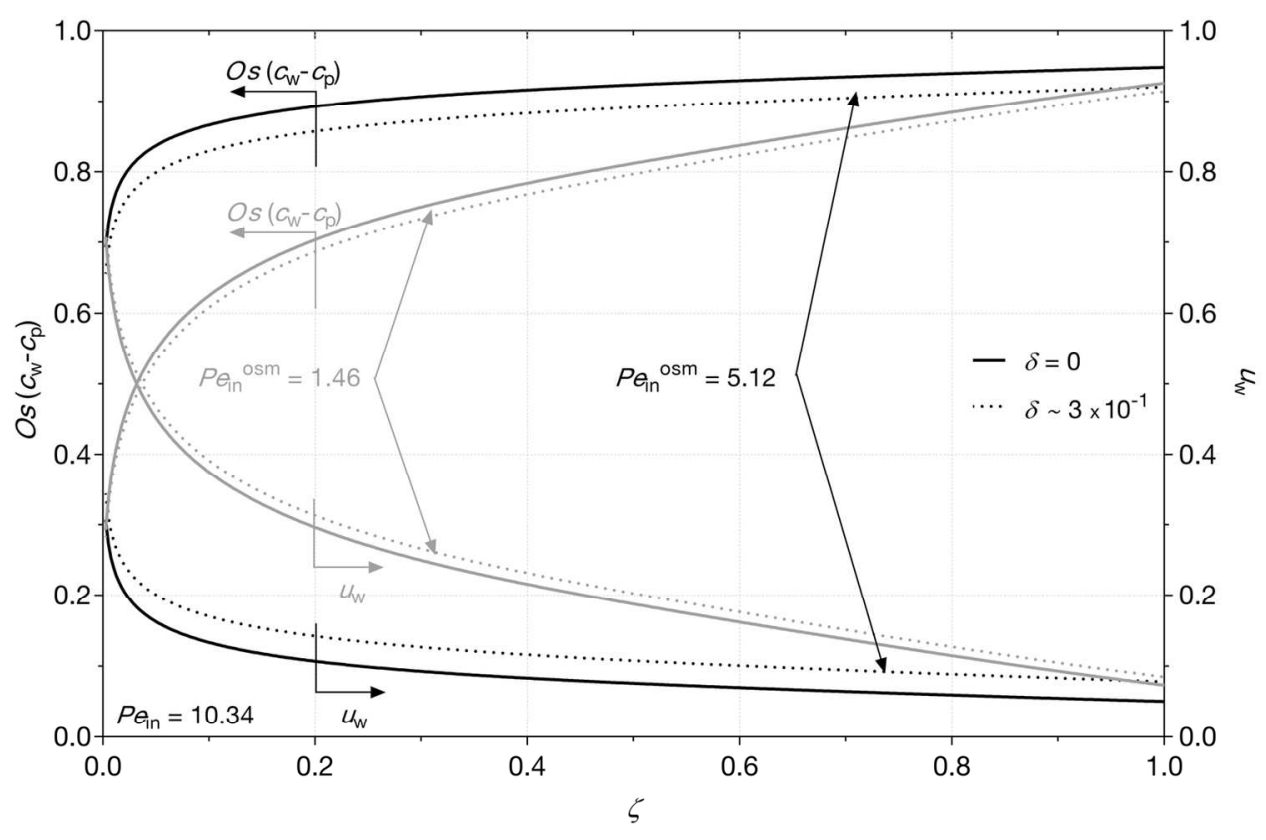

Fig. $4 a$

$144 \times 95 \mathrm{~mm}(300 \times 300 \mathrm{DPI})$ 


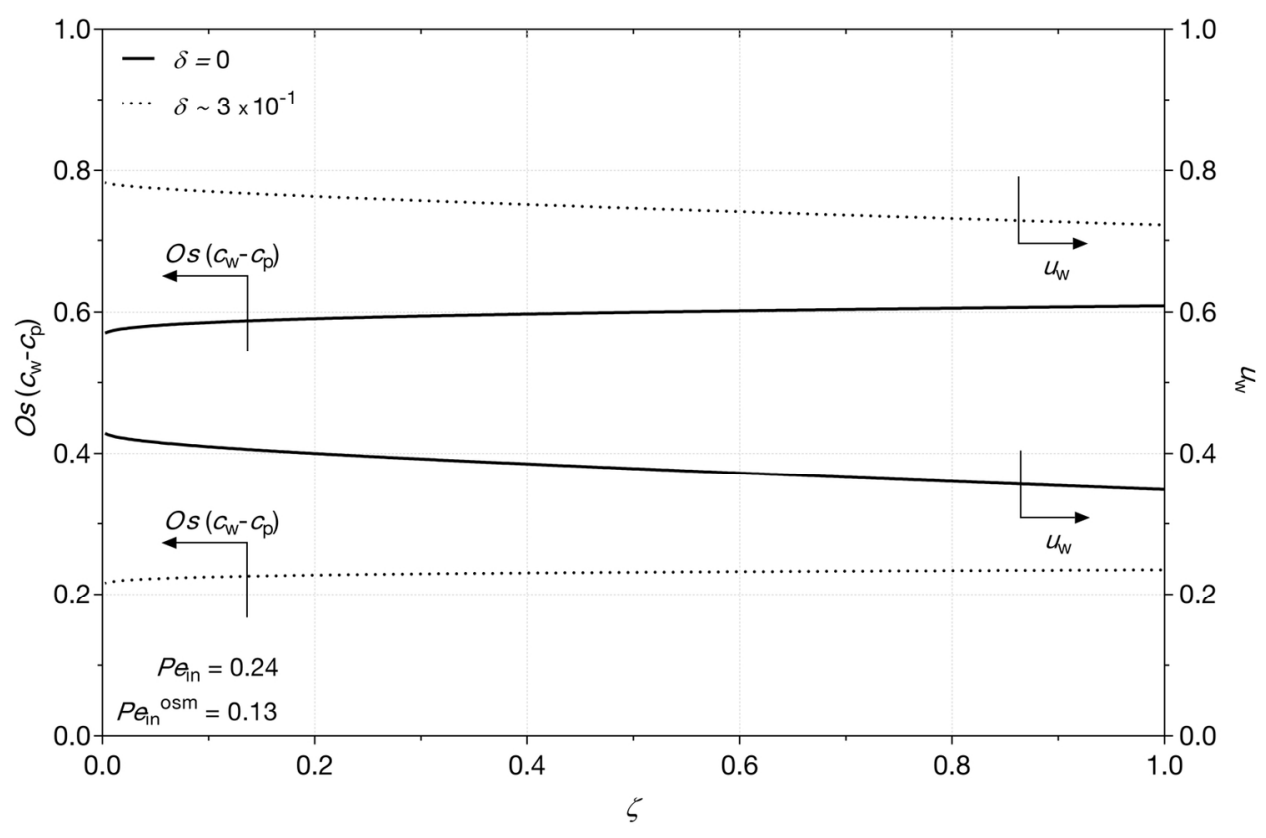

Fig. 4b

$145 \times 96 \mathrm{~mm}(300 \times 300 \mathrm{DPI})$ 


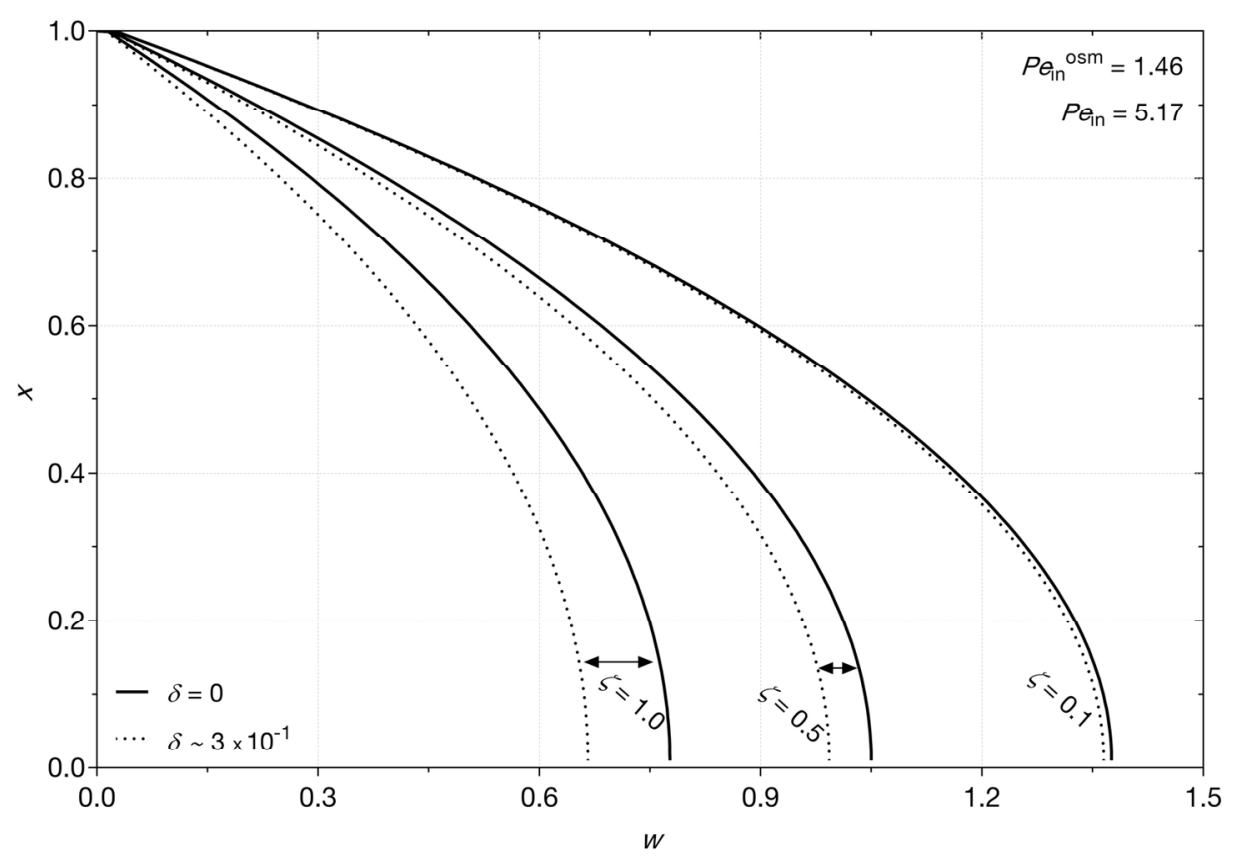

Fig. 5a

$150 \times 102 \mathrm{~mm}(300 \times 300 \mathrm{DPI})$ 


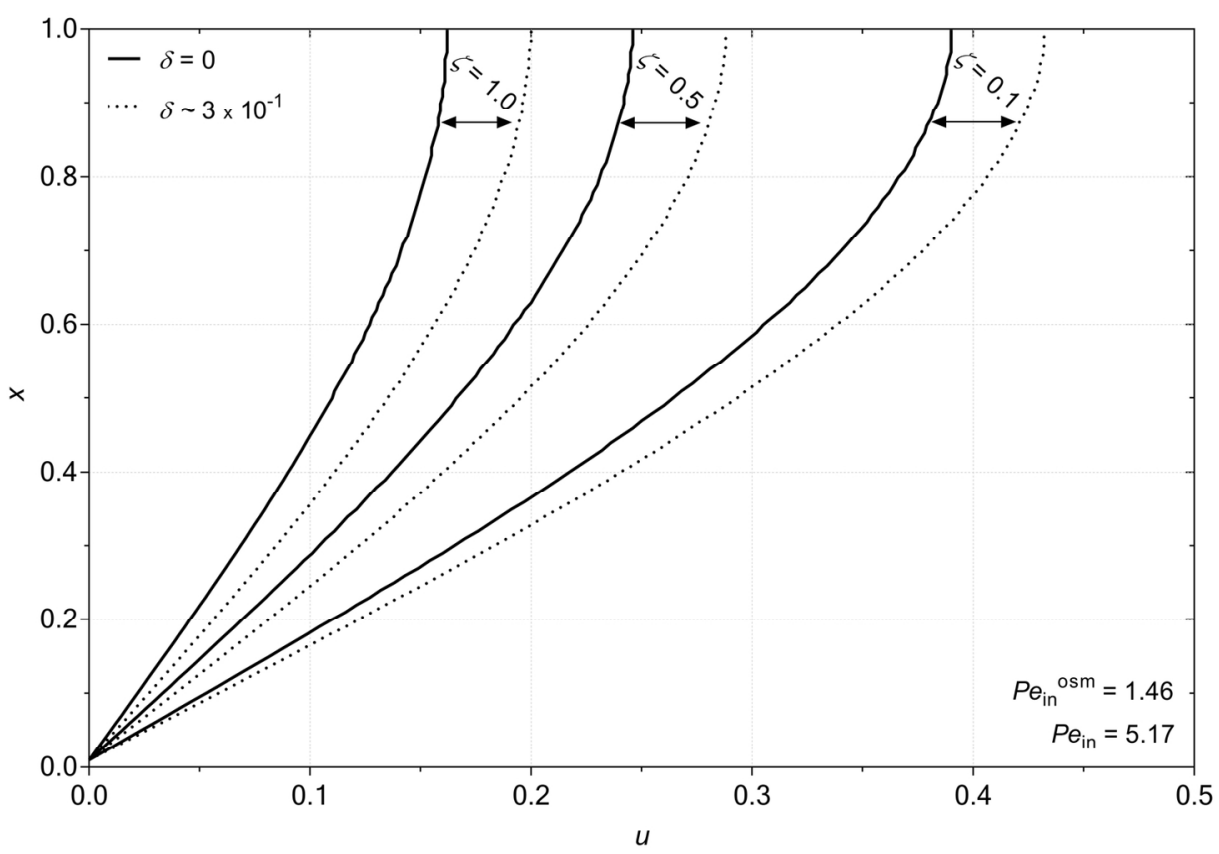

Fig. 5b

$149 \times 102 \mathrm{~mm}(300 \times 300$ DPI $)$ 


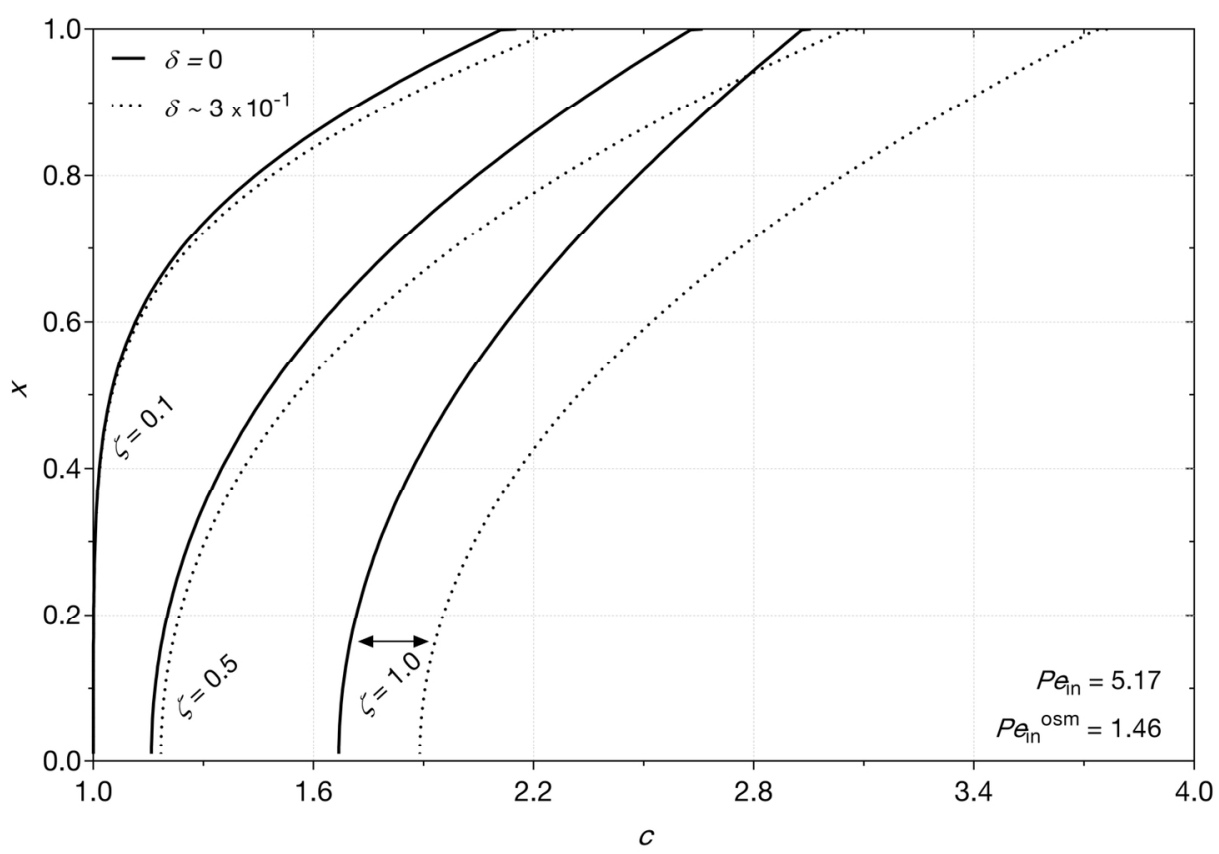

Fig. 5c

$146 \times 100 \mathrm{~mm}(300 \times 300 \mathrm{DPI})$ 


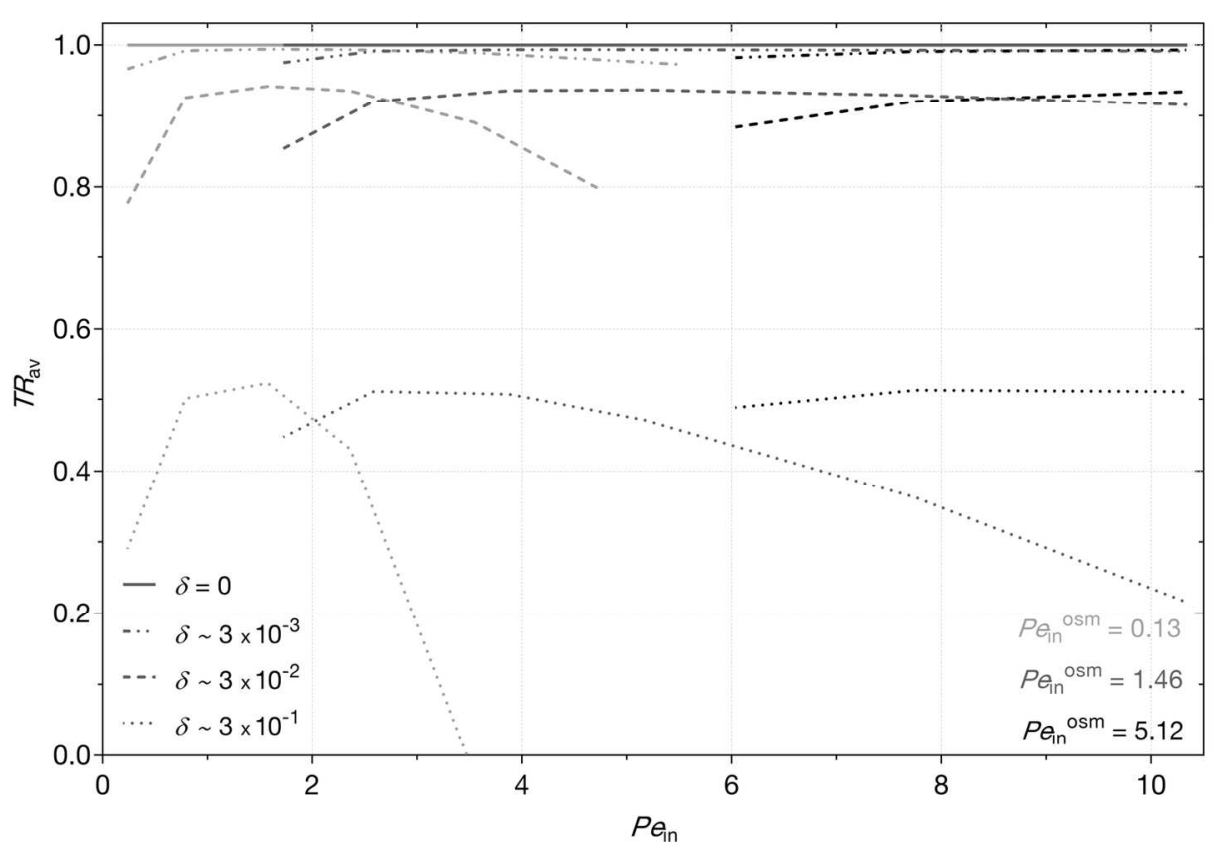

Fig. 6a

149x102mm (300 x 300 DPI)

Wiley-VCH 


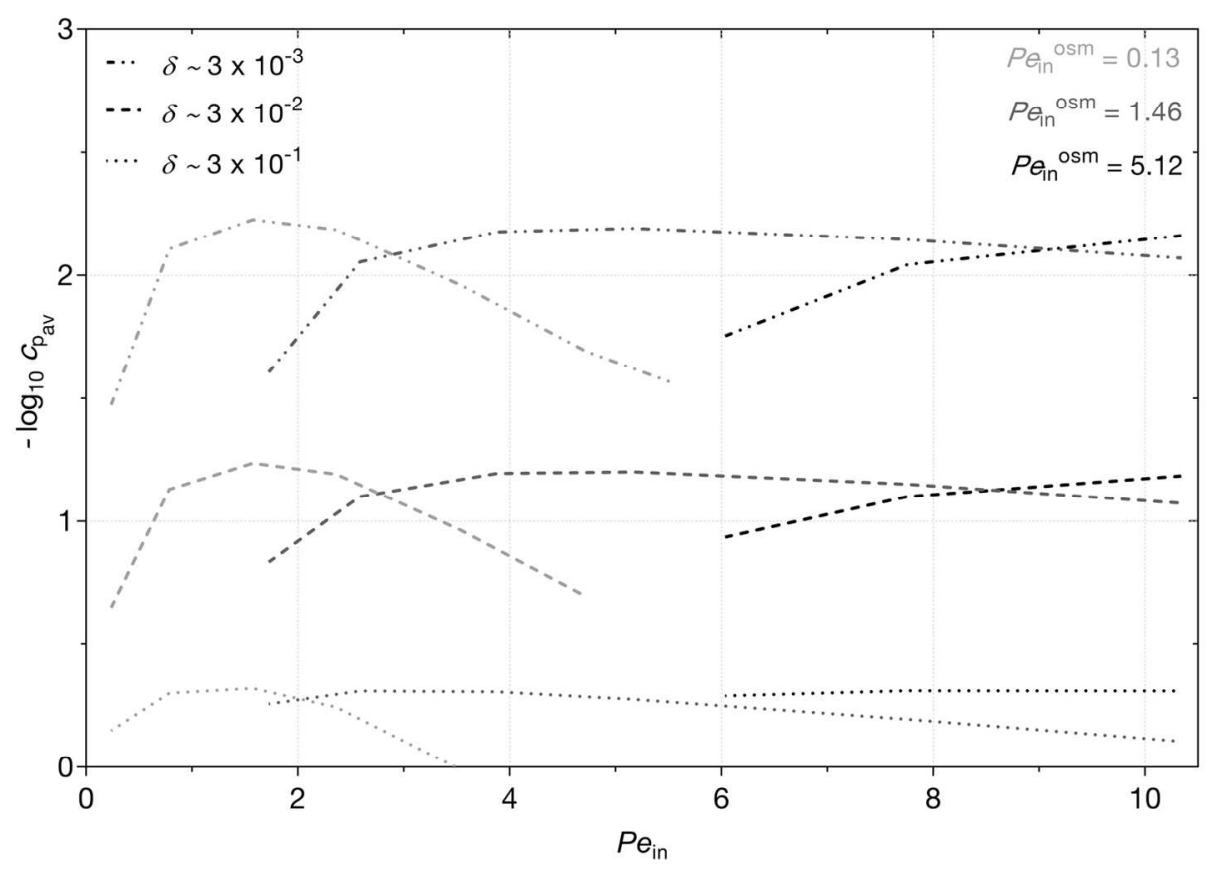

Fig. 6b

$142 \times 99 \mathrm{~mm}(300 \times 300 \mathrm{DPI})$ 


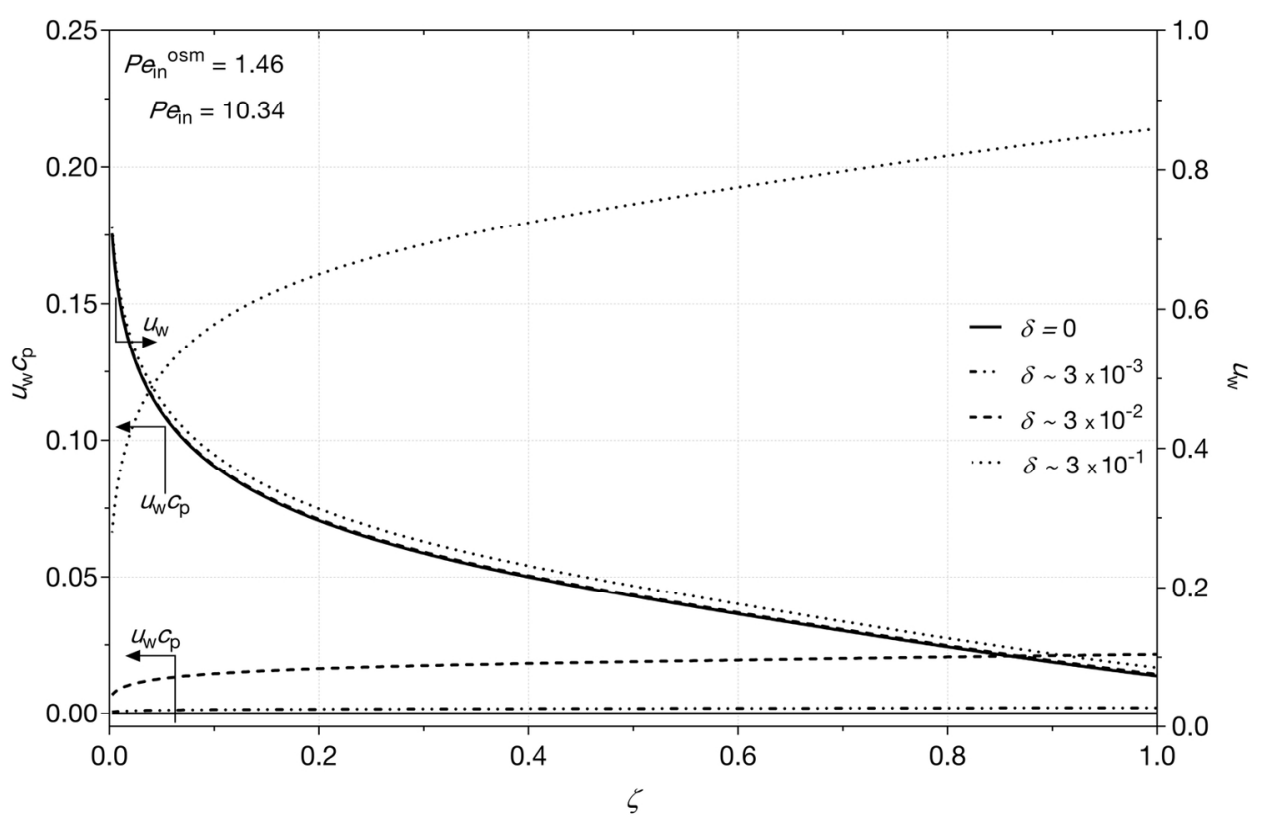

Fig. 7

$144 \times 94 \mathrm{~mm}(300 \times 300 \mathrm{DPI})$ 


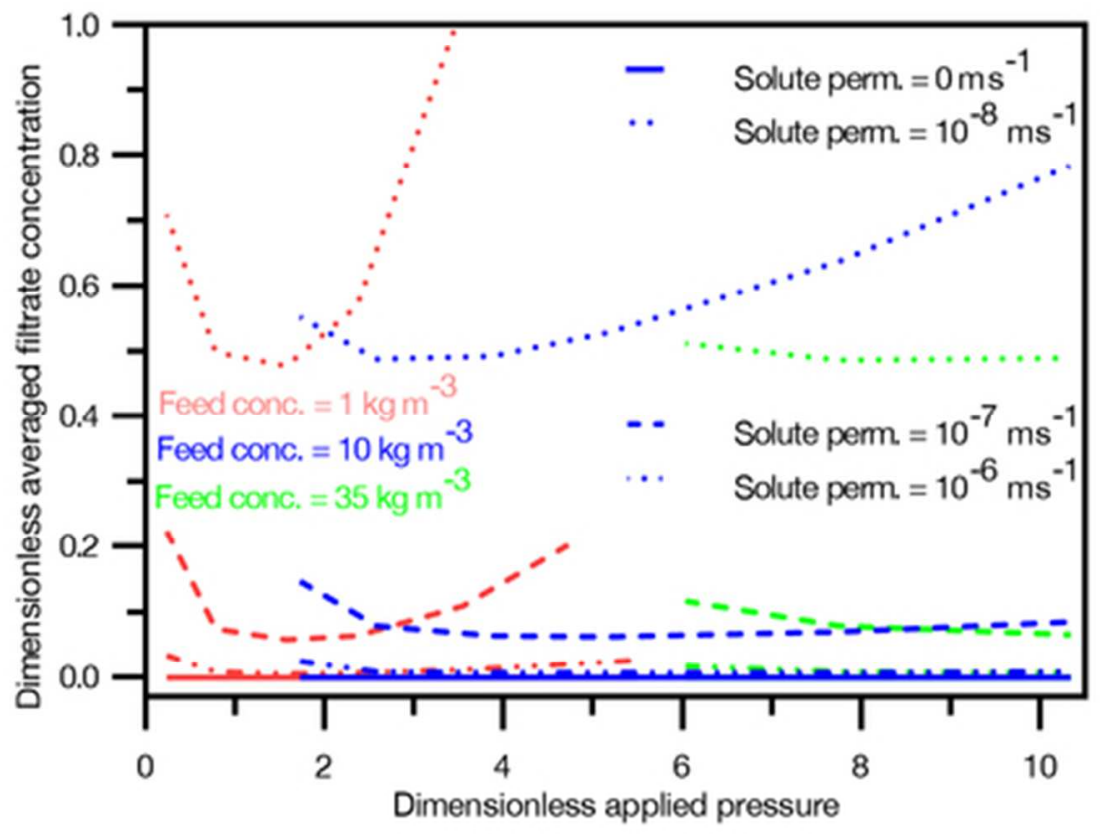

Graphical abstract

$42 \times 32 \mathrm{~mm}(300 \times 300 \mathrm{DPI})$ 